\title{
NOTA
}

\section{ATIVIDADE RADICULAR DA SOJA: DEFINIÇÃO DE UM MÉTODO ${ }^{(1)}$}

\author{
Ana Paula Encide-Olibone ${ }^{(2)}$, Dácio Olibone ${ }^{(2)} \&$ Ciro Antonio \\ Rosolem $^{(3)}$
}

\begin{abstract}
RESUMO
As técnicas de estudo radicular são trabalhosas e, dentre os métodos mais utilizados no Brasil, destacam-se a trincheira ou parede do perfil, blocos ou monólito, placa com pregos e trado. Essas técnicas utilizam amostragem destrutiva e direta das raízes. Com o objetivo de adaptar um método de avaliação da atividade radicular da cultura da soja utilizando nitrato de rubídio $\left(\mathrm{RbNO}_{3}\right)$, realizou-se um experimento em Botucatu - SP. O experimento constituiu-se de duas etapas, sendo uma em campo e outra em casa de vegetação. Plantas de soja foram cultivadas em vasos de $15 \mathrm{dm}^{3}$ de amostras de Nitossolo Vermelho em casa de vegetação. Aos 25 DAE, aplicaram-se $3 \mathrm{~mL}$ de solução de $\mathrm{RbNO}_{3}$ nas doses de 0,$0 ; 0,5 ; 1,0 ;$ e $2,0 \mathrm{mg} \mathrm{dm}^{-3} \mathrm{de}^{2}$ $\mathrm{Rb}, \mathbf{a ̀ ~} 0,05 \mathrm{~m}$ de profundidade no centro de cada vaso. A parte aérea das plantas foi coletada e separada em caule + pecíolo e limbo foliar aos dois, quatro e seis dias depois da aplicação de $\mathrm{RbNO}_{3}$. Em campo, aplicaram-se $3 \mathrm{~mL}$ de $\mathrm{RbNO}_{3}$ $\left(1,0 \mathrm{~g} \mathrm{dm}^{-3}\right.$ de $\left.\mathrm{Rb}\right)$ em diferentes distâncias da planta $(0,075,0,15$ e 0,225 m) e nas profundidades de 0,$05 ; 0,10 ; 0,20 ; 0,40 ;$ e $0,60 \mathrm{~m}$. A parte aérea das plantas foi coletada quatro dias depois da aplicação de $\mathrm{RbNO}_{3}$. A soja não apresentou fitotoxicidade ao $\mathrm{RbNO}_{3}$, o que foi eficiente na determinação da atividade radicular da cultura.
\end{abstract}

Termos de indexação: nitrato de rubídio, absorção radicular, Nitossolo Vermelho.

\section{SUMMARY: SOYBEANROOT ACTIVITY: METHODOLOGY DEFINITION}

Root study techniques are labor intensive. Among the most frequently used methods are the trench or profile wall, block or monolith, needle board and hand auger. These techniques use destructive and direct root sampling. With the objective of adapting an evaluation methodology of soybean root activity based on Rubidium Nitrate, an experiment was carried out in Botucatu, SP, Brazil, in two phases; one in the field and the other in a

\footnotetext{
(1) Parte da Tese de Doutorado da primeira autora. Apoio financeiro FAPESP. Recebido para publicação em agosto de 2006 e aprovado em novembro de 2007.

${ }^{(2)}$ Doutorando em Agricultura, Faculdade de Ciências Agronômicas, Universidade Estadual Paulista - UNESP. Rua José Barbosa de Barros 1780, Caixa Postal 237, CEP 18610-307 Botucatu (SP). E-mail: encide@fca.unesp.br; olibone@fca.unesp.br

(3) Professor Titular do Departamento de Produção Vegetal, FCA/UNESP. E-mail: rosolem@fca.unesp.br
} 
greenhouse. Soybean plants were grown in $15 \mathrm{~L}$ pots. $25 \mathrm{DAE}, 3 \mathrm{~mL}$ of Rubidium Nitrate solution was applied at 0; 0.5; 1.0 and $2.0 \mathrm{mg} \mathrm{dm}^{-3}$, at a depth of $0.05 \mathrm{~m}$ in the middle of each pot. The plants shoot was collected and divided in stalk + petiole and leaf after 2, 4 and 6 days of $\mathrm{RbNO}_{3}$ application. In the field, portions of $3.0 \mathrm{~mL} \mathrm{RbNO} \mathrm{N}_{3}$ were applied at depths of $0.05 ; 0.10 ; 0.20 ; 0.40$ and $0.60 \mathrm{~m}$. The plant shoot was collected 4 days after $\mathrm{RbNO}_{3}$ applications. No phytotoxicity of $\mathrm{RbNO}_{3}$ to soybean plants was observed. $\mathrm{RbNO}_{3}$ was efficient to determine root activity.

Index terms: Rubidium nitrate, root uptake, Red Nitosol.

\section{INTRODUÇÃO}

O estudo do sistema radicular pode ser realizado por várias técnicas, desde aquelas mais simples ou de menor técnica até as de recursos avançados. A adoção de um método varia em função do objetivo do trabalho a ser realizado, das características avaliadas e principalmente dos recursos disponíveis. As técnicas comumente empregadas avaliam diretamente o sistema radicular da planta com grande mobilização de solo e significativa amostragem de material vegetal, caracterizando métodos trabalhosos e que requerem muito tempo.

Essas técnicas podem ser divididas, segundo Böhm (1979), em métodos diretos e indiretos. Os métodos diretos, como placa com pregos, blocos ou monólito, trincheira ou parede do perfil, consistem em cavar uma trincheira ao lado da planta, de modo a expor as raízes. Depois, as raízes são contadas e registradas, diferindo-se cada método em algumas particularidades de amostragem e avaliação. No entanto, nessas técnicas diretas ocorre grande perda de parcela do experimento por causa do volume de solo mobilizado. O método do trado também é uma técnica direta, porém dispensa a abertura da trincheira, uma vez que são retiradas apenas amostras de solo, sem destruição da área amostrada (Böhm, 1979; Fujiwara et al., 1994).

Os métodos de estudo radicular indireto são baseados na determinação de taxas de mudança de água ou nutrientes no perfil do solo, inferindo-se a distribuição e a atividade radicular. A técnica indireta mais comum para a determinação da atividade radicular é através de elemento marcado ou radioativo $\left({ }^{32} \mathrm{P},{ }^{42} \mathrm{~K},{ }^{45} \mathrm{Ca},{ }^{137} \mathrm{Cs},{ }^{134} \mathrm{Cs}\right.$ e $\left.{ }^{86} \mathrm{Rb}\right)$. Com o uso de solução contendo marcador no solo, o sistema radicular da planta é indiretamente avaliado e sua atividade inferida (Böhm, 1979).

A técnica do elemento não marcado tem vantagem em sua simplicidade e baixo nível tecnológico. Sayre \& Morris (1940) mensuraram a extensão do sistema radicular do milho com a utilização de pequenas doses de $\mathrm{LiCl}$ aplicadas nas entrelinhas da cultura e, nas folhas das plantas, determinaram a ausência ou presença do elemento na planta. No entanto, Fox \& Lipps (1964) utilizaram Li para estimar a atividade radicular de alfafa e constataram que, mesmo em baixos teores, esse elemento foi tóxico às plantas.
A fitotoxicidade e distribuição irregular na planta são alguns dos problemas do uso de elementos não marcados. Nesse sentido, o Rb é um elemento que expressa de maneira satisfatória a atividade radicular das plantas porque é considerado análogo ao K (Epstein, 1961; Epstein et al., 1963). Esses autores utilizaram $\mathrm{RbCl}$ e $\mathrm{Rb}_{2} \mathrm{SO}_{4}$, respectivamente, em suas pesquisas. Com inúmeras utilidades na forma radioativa, o uso de $\mathrm{Rb}$ no estudo de raízes pode ser viável devido às suas características similares às do Ke por apresentarse disponível nas formas de cloreto, fosfato, sulfato e nitrato. Além disso, pode ser usado um isótopo não radioativo, o que significa redução de riscos ecológicos. Assim, as doses tornam-se mais exatas, uma vez que o elemento não faz parte dos fertilizantes e corretivos e não é essencial às plantas.

Considerando que há quase sempre grande concentração radicular na camada arável, e que o solo, em profundidade, normalmente é pobre em nutrientes (Raij, 2001), técnicas de avaliação da atividade radicular devem expressar a verdadeira contribuição das raízes à ciclagem de nutrientes em sistema de semeadura direta. Nesse sentido, o trabalho objetivou adaptar um método de avaliação da atividade radicular para a cultura da soja utilizando $\mathrm{RbNO}_{3}$.

\section{MATERIAL E MÉTODOS}

O experimento foi realizado na Fazenda Experimental Lageado, Faculdade de Ciências Agronômicas - UNESP - Botucatu - SP, e constituiuse de duas etapas, uma em casa de vegetação e outra em campo.

\section{Etapa 1: Teste em casa de vegetação}

Realizada em novembro de 2005, com delineamento inteiramente casualizado, em esquema fatorial $4 \times 3$, ou seja, quatro concentrações de Rb e três épocas de coleta e seis repetições. O experimento foi composto por 24 vasos $\left(15 \mathrm{dm}^{3}\right)$ com três plantas de soja (Cultivar BRS 216) por vaso, que continha material proveniente de um Nitossolo Vermelho, no qual acrescentaram-se $40 \mathrm{~g}$ da fórmula 4-14-8. Decorridos 25 dias após a emergềncia (DAE), aplicaram-se, com auxílio de uma seringa e um catéter, $3 \mathrm{~mL}$ de solução de $\mathrm{RbNO}_{3}$ nas doses de $0 ; 0,5 ; 1,0 ;$ e $2,0 \mathrm{mg} \mathrm{dm}^{-3}$, sendo a aplicação feita a $0,05 \mathrm{~m}$ de profundidade no centro 
de cada vaso. Aos 2,4 e 6 dias após a aplicação do $\mathrm{RbNO}_{3}$, a parte aérea das plantas foi coletada e separada em caule + pecíolo e limbo foliar para quantificação do teor de Rb e de sua distribuição na planta. O material coletado foi levado à estufa de ventilação forçada a $65^{\circ} \mathrm{C}$ por $72 \mathrm{~h}$, para secagem e, posteriormente, foi pesado. Em seguida, realizou-se a moagem das amostras para digestão nitroperclórica (Malavolta et al., 1997) e determinação do teor de Rb pelo ICP.

Os dados foram submetidos à análise de variância e as médias comparadas pelo teste t (LSD) a $5 \%$. A comparação entre épocas de aplicação foi feita pelo t e para doses utilizou-se análise de regressão.

\section{Etapa 2: Teste em campo}

Pelos resultados obtidos na Etapa 1, obteve-se suporte para, em janeiro de 2006, realizar-se a Etapa 2 do experimento em campo, em Nitossolo Vermelho. Semeou-se soja (cultivar Embrapa 48) em sistema de semeadura direta sobre palhada de milheto. No estádio pleno de florescimento (65 DAE) da cultura, aplicaramse $3 \mathrm{~mL}$ de $\mathrm{RbNO}_{3}$ na dose de $1,0 \mathrm{mg} \mathrm{dm}^{-3}$. Nessa etapa, a solução foi aplicada, no solo úmido, por um orifício aberto com uma haste de aço e com auxílio de uma seringa e um catéter a $0,075,0,15$ e $0,225 \mathrm{~m}$ da planta de referência e nas profundidades 0,$05 ; 0,10$; 0,$20 ; 0,40$; e $0,60 \mathrm{~m}$ do solo, em cinco repetições. O delineamento experimental utilizado foi o inteiramente casualizado, em esquema fatorial 3 x 5 , ou seja, três distâncias de aplicação e cinco profundidades, e testemunha sem aplicação de $\mathrm{Rb}$, com cinco repetições. Decorridos quatro dias da aplicação de $\mathrm{RbNO}_{3}$, a parte aérea das plantas foi coletada e separada em caule e folhas e não mais como realizada na Etapa 1, pois os teores de $\mathrm{Rb}$ determinados no pecíolo não foram bom indicativo de atividade radicular. Os procedimentos de análise do tecido vegetal foram os mesmos descritos na Etapa 1. Diante dos teores no tecido vegetal, convencionou-se que o maior teor de $\mathrm{Rb}$ observado corresponderia a $100 \%$ de atividade radicular. Dessa forma, estimaram-se a atividade radicular para as demais distâncias da planta referência e profundidade de aplicação.

\section{RESULTADOS E DISCUSSÃO}

\section{Etapa 1: Teste em casa de vegetação}

As plantas de soja absorveram o Rb independentemente da dose aplicada, e visualmente não foi constatada fitotoxicidade para as doses empregadas, nem mesmo sob a maior delas, ao contrário do que foi observado por Fox \& Lipps (1964) quando utilizaram $\mathrm{Li}$ em alfafa. Os resultados dos teores de $\mathrm{Rb}$ no pecíolo + caule não mostraram interação entre as doses e épocas de aplicação; portanto, não foi possível determinar qual a época ideal para a avaliação após a aplicação (Quadro 1).

Quadro 1 Teor de rubídio na parte aérea (pecíolo + caule e limbo foliar) de plantas de soja submetidas à aplicação de diferentes concentrações de rubídio, em diferentes épocas de avaliação

\begin{tabular}{|c|c|c|c|c|}
\hline \multirow[b]{2}{*}{ Dose de Rb } & \multicolumn{4}{|c|}{ Teor de Rb } \\
\hline & $2 \mathbf{D A A}^{(1)}$ & 4 DAA & 6 DAA & Média \\
\hline \multirow[t]{2}{*}{$\mathrm{mg} \mathrm{dm}{ }^{-3}$} & \multicolumn{4}{|c|}{$\mathrm{mg} \mathrm{kg}^{-1}$} \\
\hline & \multicolumn{4}{|c|}{ Pecíolo + caule } \\
\hline 0 & $9 \mathrm{~b}$ & $24 \mathrm{~b}$ & $41 \mathrm{~b}$ & $25 \mathrm{c}$ \\
\hline 0,5 & $177 \mathrm{ab}$ & $155 \mathrm{~b}$ & $143 \mathrm{~b}$ & $159 \mathrm{bc}$ \\
\hline 1,0 & $377 \mathrm{ab}$ & $356 \mathrm{~b}$ & $371 \mathrm{ab}$ & $368 \mathrm{~b}$ \\
\hline 2,0 & $591 \mathrm{a}$ & $948 \mathrm{a}$ & $570 \mathrm{a}$ & $703 \mathrm{a}$ \\
\hline Média & 289 & 370 & 281 & - \\
\hline \multirow[t]{2}{*}{ DMS } & \multicolumn{4}{|c|}{239,4} \\
\hline & \multicolumn{4}{|c|}{ Limbo foliar } \\
\hline 0 & $49 \mathrm{aA}$ & $90 \mathrm{bA}$ & $37 \mathrm{bA}$ & $59 \mathrm{~b}$ \\
\hline 0,5 & $90 \mathrm{aA}$ & $114 \mathrm{bA}$ & $63 \mathrm{bA}$ & $89 \mathrm{~b}$ \\
\hline 1,0 & 186 aA & $607 \mathrm{aA}$ & $310 \mathrm{abA}$ & $368 \mathrm{a}$ \\
\hline 2,0 & $297 \mathrm{aB}$ & 880 aA & 588 aAB & $588 \mathrm{a}$ \\
\hline Média & $155 \mathrm{~B}$ & $423 \mathrm{~A}$ & $250 \mathrm{AB}$ & - \\
\hline DMS & \multicolumn{4}{|c|}{275,91} \\
\hline
\end{tabular}

\footnotetext{
(1) DAA: dias após a aplicação. Médias seguidas pela mesma letra minúscula na coluna e maiúscula na linha, não diferem entre si, pelo teste $\mathrm{t}$ (LSD) a $5 \%$.
} 
Para limbo foliar, verificou-se que as doses de 1,0 e 2,0 $\mathrm{mg} \mathrm{dm}^{-3}$ de Rb são suficientes para quantificar o teor de $\mathrm{Rb}$ na matéria seca das plantas durante o período de avaliação (Quadro 1). Com o intuito de reduzir custos, adotou-se $1,0 \mathrm{mg} \mathrm{dm}^{-3}$ como a melhor dose.

Mediante os teores de Rb no pecíolo + caule e limbo foliar, observou-se que não há necessidade de separação da folha em limbo e pecíolo, de modo que as avaliações podem ser realizadas apenas em folha ou caule, o que diminui o número de amostras utilizadas.

Quanto ao tempo de coleta, os resultados para as doses 1,0 e $2,0 \mathrm{mg} \mathrm{dm}^{-3}$ demonstraram que um período superior a quatro dias após a aplicação de $\mathrm{Rb}$ é suficiente para que o elemento seja translocado das raízes à parte aérea da soja (Quadro 1), o que facilitará, em futuras avaliações, a amostragem, podendo ser coletadas apenas folhas da cultura estudada.

\section{Etapa 2: Teste em campo}

A atividade radicular obtida pela quantificação do teor de $\mathrm{Rb}$ na folha (Figura 1a) não foi diferente daquela observada a $0,075,0,15$ e $0,225 \mathrm{~m}$ da planta de referência para as profundidades 0,$05 ; 0,20 ; 0,40$; e $0,60 \mathrm{~m}$. Houve diferença significativa somente para a profundidade de $0,10 \mathrm{~m}$, o que pode ser atribuído ao fato de haver raízes em maior densidade próximas da planta, ou seja, 0,075 e 0,15 m.

Quanto à atividade radicular obtida pela quantidade de $\mathrm{Rb}$ no caule (Figura $1 b$ ), não foi diferente a 0,075 , 0,15 e $0,225 \mathrm{~m}$ da planta de referência para as profundidades 0,$10 ; 0,20$; e $0,60 \mathrm{~m}$. Houve diferença significativa somente para a profundidade de $0,05 \mathrm{e}$ $0,40 \mathrm{~m}$.

A média de atividade radicular das plantas de soja medida pelo teor de Rb observado nas folhas e caule não apresentou diferença significativa. Foi observada diferença significativa entre os teores nas profundidades de 0,10 e 0,20 m, e o teor foi maior no caule (Figura 1c).

(a)

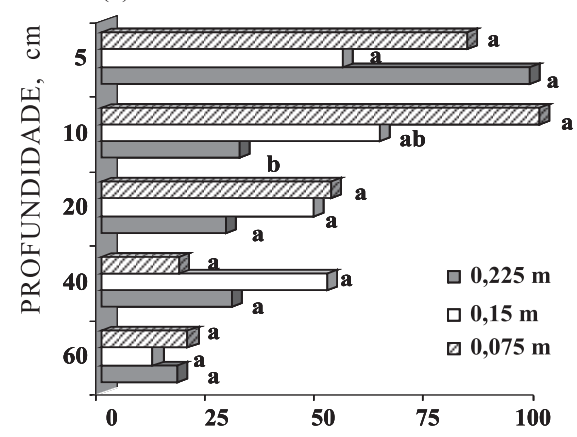

(b)

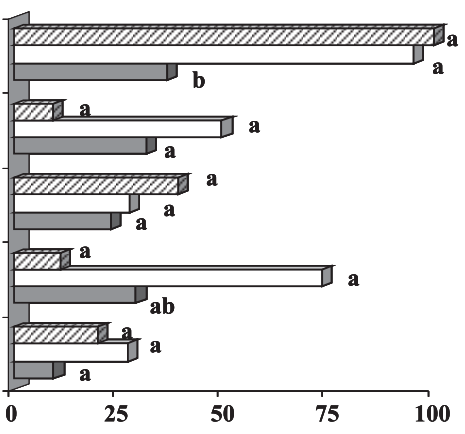

$\mathrm{O}$ sistema radicular apresentou maior atividade nas camadas superficiais do solo e a $0,075 \mathrm{~m}$ de distância da planta, quando se interpretam os teores foliares de Rb. Para os teores no caule, observou-se a mesma tendência em relação à atividade radicular a $0,15 \mathrm{~m}$ da planta. Assim, os teores do elemento nas folhas representaram atividade radicular mais próxima do que seria esperado tendo em vista a literatura sobre arquitetura radicular (Allan Jones et al., 1991; Fitter, 1996; Lynch \& Nielsen, 1996; Berntson, 1996).

A aplicação de $3 \mathrm{~mL}$ de $\mathrm{Rb}$, na dose de $1 \mathrm{mg} \mathrm{dm}^{-3}$, possibilitou a quantificação de $\mathrm{Rb}$ absorvido pela cultura da soja, o que torna essa prática de avaliação de atividade radicular indireta simples, rápida, eficiente, além de ausência de sintomas de fitotoxicidade na planta e rápida absorção.

$\mathrm{O}$ uso de $\mathrm{RbNO}_{3}$ para avaliação da atividade radicular mostrou resultados satisfatórios porque foi absorvido em teores detectáveis no tecido vegetal, o que torna possível inferir que o uso de $\mathrm{Rb}$ radioativo é dispensável para esta avaliação, evitando assim técnicas mais caras e com maiores complexidades técnicas. Outra vantagem da técnica foi a redução de perdas das parcelas experimentais, porque coleta-se apenas a parte aérea das plantas identificadas, sem a necessidade de amostragem de raízes, o que reduz a mobilização de solo e as perdas de área útil. Além disso, a técnica mimetiza a absorção de K (Epstein, 1961; Epstein et al., 1963), permitindo a estimativa da atividade radicular, e não apenas da presença de raízes.

\section{CONCLUSÕES}

1. $\mathrm{O} \mathrm{RbNO}_{3}$ nas doses de 0,$5 ; 1,0$; e $2,0 \mathrm{mg} \mathrm{dm}^{-3}$ não apresentou efeito fitotóxico à cultura da soja, sendo eficiente na determinação indireta da sua atividade radicular.

ATIVIDADE RADICULAR, \%

(c)

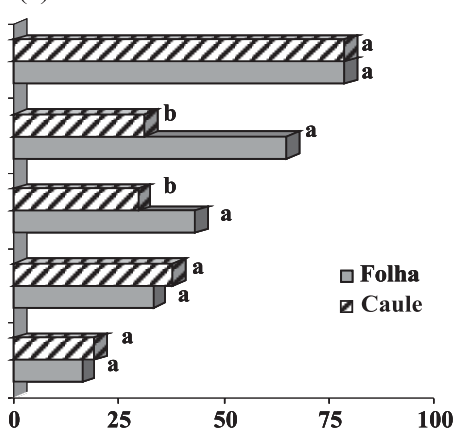

Figura 1. Atividade radicular estimada de plantas de soja aos quatro dias após a aplicação de $3 \mathrm{~mL}$ de $\mathrm{RbNO}_{3}$ na dose de $1 \mathrm{mg} \mathrm{dm}{ }^{-3}$, a $0,075,0,15$ e $0,225 \mathrm{~m}$ de distância da planta e a 0,$05 ; 0,10 ; 0,20 ; 0,40 ; \mathrm{e}$ 0,60 $\mathrm{m}$ de profundidade: (a) obtida pelo teor de rubídio em folhas; (b) obtida pelo teor de rubídio no caule; e (c) obtida com as médias dos teores de rubídio em folhas e no caule. 
2. O uso dessa adaptação de método tem fácil aplicação no campo com resultados satisfatórios para a determinação da atividade radicular, além de ser uma técnica de amostragem não destrutiva e sem grandes perdas de parcela.

\section{LITERATURA CITADA}

ALLAN JONES, C.; BLAND, W.L.; RITCHIE, J.T. \& WILLIAMS, J.R. Simulation of root growth. In.: HANKS, R.J. \& RITCHIE, J.T., eds. Modeling plant and soil systems. Madison, 1991. p.91-123. (Agronomy Monograph, 31)

BÖHM, W. Methods of studying root system. Berlin, SpringerVerlag, 1979. 188p.

BERNTSON, G.M. Fractal geometry, scaling and the description of plant root architecture. In: WAISEL, Y.; ESHEL, A. \& KAFKAFI, U., eds. Plant roots: The hidden half. 2.ed. New York, Dekker, 1996. p.259-272.

EPSTEIN, E. The essential role of calcium in selective cation transport by plant cells. Plant Physiol., 36:437-444, 1961.

EPSTEIN, E.; RAINS, D.W. \& ELZAM, O.E. Resolution of dual mechanisms of potassium absorption by barley roots. Proc. National Acad. Sci. USA, 49:684-692, 1963.
FITTER, A. Characteristics and function of root systems. In: WAISEL, Y.; ESHEL, A. \& KAFKAFI, U., eds. Plant roots: The hidden half. 2.ed. New York, Dekker, 1996. p.1-20.

FOX, R.L. \& LIPPS, R.C. A comparison of stable strontium and $\mathrm{P}^{32}$ as tracers for estimating alfalfa root activity. Plant Soil, 20:337-350, 1964.

FUJIWARA, M.; KURACHI, S.A.H.; ARRUDA, F.B.; PIRES, R.C. M. \& SAKAI, E. A técnica de estudo de raízes pelo método do trado. Campinas, Instituto Agronômico de Campinas, 1994. (Boletim Técnico, 153)

LYNCH, J. \& NIELSEN, K.L. Simulation of root system architecture. In: WAISEL, Y.; ESHEL, A. \& KAFKAFI, U., eds. Plant roots: The hidden half. 2.ed. New York, Dekker, 1996. p.247-257.

MALAVOLTA, E.A.; VITTI, G.C. \& OLIVEIRA, S.A. Avaliação do estado nutricional das plantas: Princípios e aplicações. Piracicaba, Potafós, 1997. 201p.

RAIJ, B. van; ANDRADE, J.C.; CANTARELLA, H. \& QUAGGIO, J.A. Análise química para avaliação da fertilidade de solos tropicais. Campinas, Instituto Agronômico, 2001. 285p.

SAYRE. J.D. \& MORRIS, V.H. The lithium method of measuring the extent of corn root systems. Plant Physiol., 15:761-764, 1940. 